\title{
Matryoshka and Perfect Language Resolution. On the Complex Art of Writing Abstracts
} are very short, careless, without proper labeling, the so-called keywords or - especially in the case of humanists - very broad, containing unnecessary embellishments. The necessity to publish in journals indexed in international databases - introduced by the recent amendments to the law on science in Poland - forces the familiarization with the basics of "abstractology." Changes in the directions of development of Polish science can already be seen in the latest announcements regarding research funding. It is enough to look at the latest guidelines of the funders, for example, the competition "OPUS21" of the National Science Center [NCN - polish research funding agency], in which the indicated publication paths are recommended by journals published in the open-access model - the first path is the periodicals from the DOAJ list. The third path refers to open publishing programs. Most of the journals that meet the criteria are indexed in databases that expect specific, standardized metadata from authors, including a good abstract.

\section{Speleologist - caveologist - cave explorer - caveman?}

In April 2021, an article by two young Italian biologists about the art of writing abstracts was published $^{1}$. Alejandro Martínez is an evolutionary biologist, and Stefano Mammola is an ecologist, both of whom work at the National Research Council in Pallanza, Italy. Using Web of Science, an online platform that allows subscribers to access databases of scientific publications, they collected and analyzed 21,486 articles devoted to the study of caves. Speleology

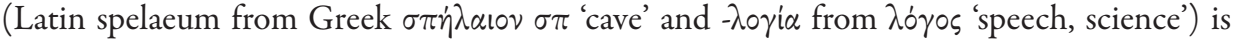
the study of caves. Speleologists study such issues as the genesis and development of caves,

1 Martínez A., Mammola S., Specialized terminology reduces the number of citations of scientific papers, "Proceedings of the Royal Society B: Biological Sciences", 288, no. 1948 (14.04.2021): 2020-2581. DOI: 10.1098/ rspb.2020.2581. 
microclimate, water relations, animate nature - flora and fauna, etc. They are interested in environmental protection issues. Caves are also explored in the fields of geology, hydrogeology, paleontology, archaeology, and tourism. A speleologist can also do sports, a kind of underground mountaineering - that is another story. Recently, the caves have also become a place of research on bats, which — as we know - are extremely important for virology and epidemiology. Why are we bringing this topic up?

It is time for a little mental experience. Let us read the sentence:

Today I visited two dark places underground where many animals live.

Is this an understandable sentence? It was "produced" using the 1000 most frequently used words in the English language, then translated into Polish for the essay.

Initially, the sentence was to read:

Today I was in two caves known for their biodiversity.

- but such a sentence is not accepted by the program that checks if we use the right words, i.e. the most common words in use ${ }^{2}$.

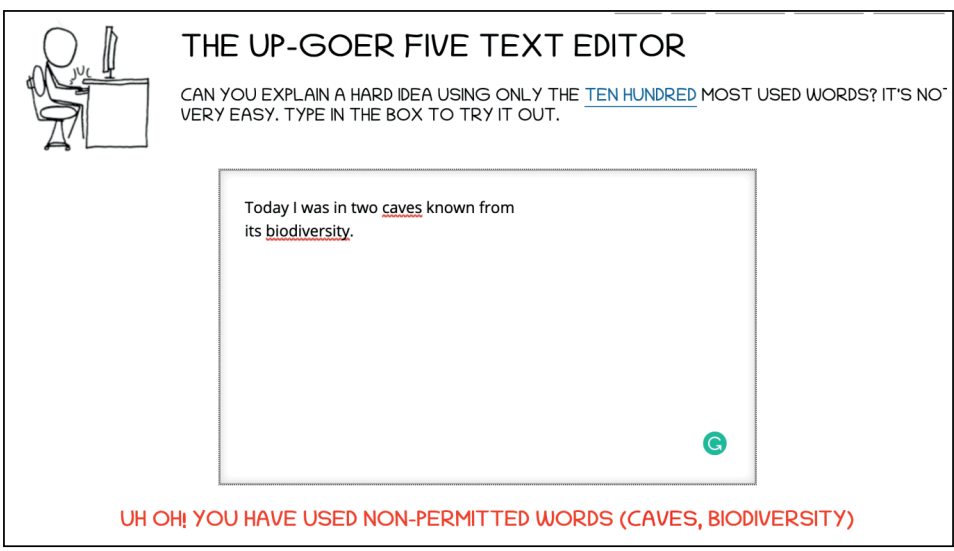

Figure 1. Computer screenshot of test results with The Up-Goer Five Text Editor (JP).

2 The program is available free online: www.ef.edu/english-resources/english-vocabulary/top-1000-words/. A program that checks the difficulty level of English texts: splasho.com/upgoer5/. For Polish texts there is a program that works on a similar principle: www.jasnopis.pl. Of course these are not ideal tools, as they sometimes suggest simplifications bordering on the absurd, but they illustrate a certain problem and can also be used for fun. 
What is the abstract of an article published in an internationally recognized journal submitted to the program?

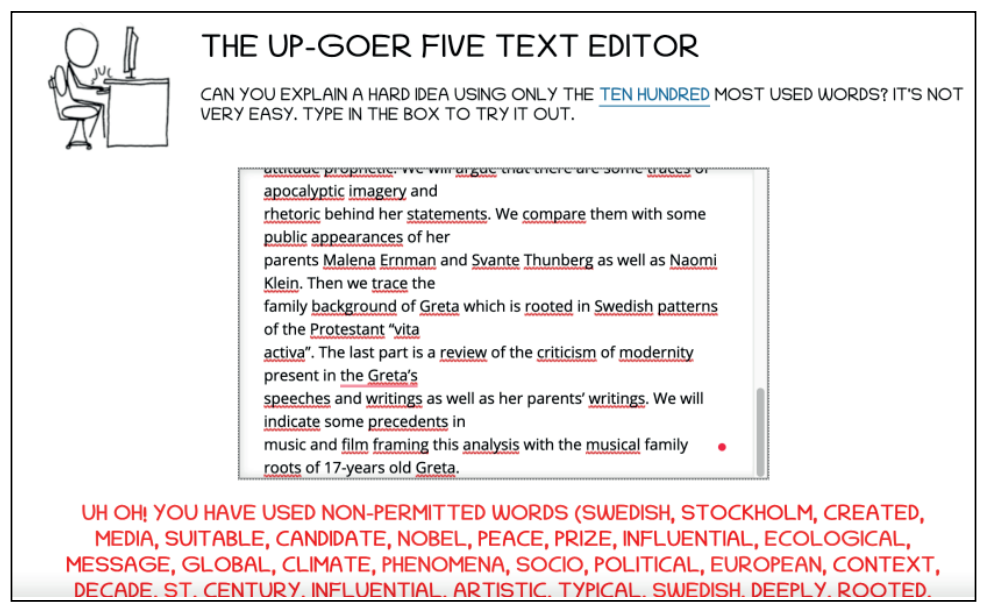

Figure 2: Article abstract [author - J.P.] analyzed by The Up-Goer Five Text Editor: splasho.com/upgoer5/

And the Polish example?

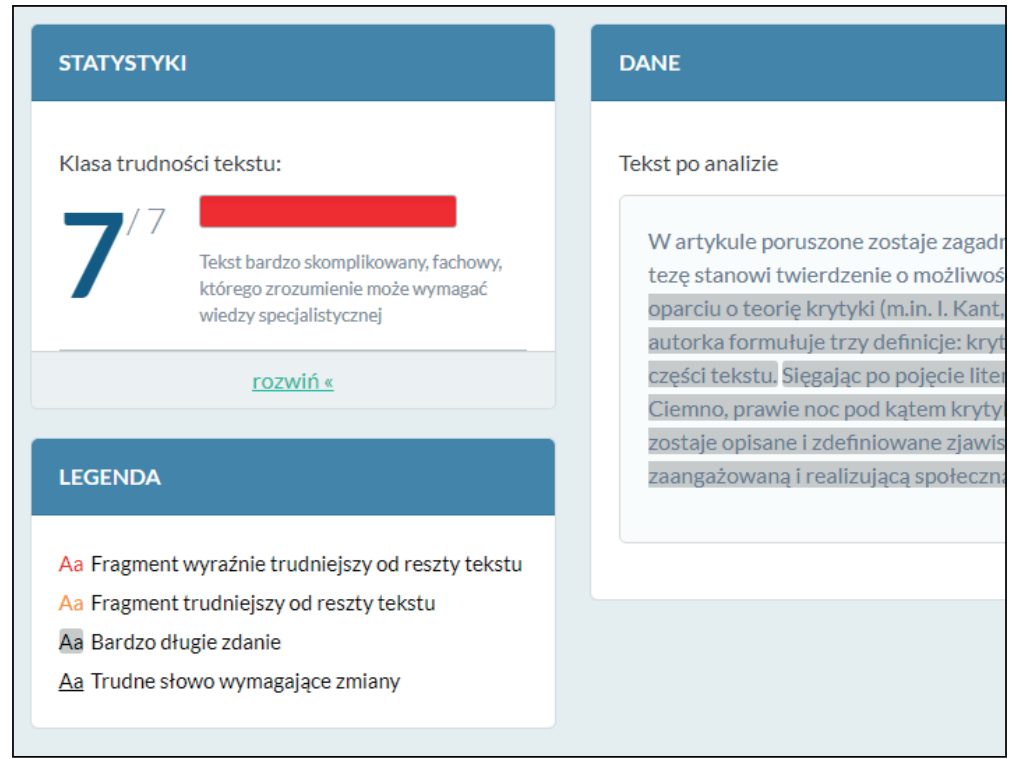

Figure 3: Article abstract [author - A.Z.] analyzed by Jasnopis: www.jasnopis.pl/ [A very difficult text, requiring specialized knowledge.] 
It may sound like fun, but we are dealing with a severe scientific and social problem. The language we use determines many things in our lives, also in scientific life. It is relatively common to believe that the richer the vocabulary, the richer the knowledge of the world. The famous example with colour names is often used to explain the magic of a dictionary: an ordinary language user, an amateur, uses up to twenty colour names every day, while an artist (a painter) dealing with the arts uses nearly a hundred colour names!

It would seem that the more detailed the world view, the more complex the language we need. Nevertheless - the more detailed the language we use, the less communicative we become. Moreover, we lock ourselves in our ivory towers.

A metaphor about resolution could be used here: the possibility of understanding and grasping mentally is also determined by the correct resolution: if it is too small, we disregard the message as not very expert, and if it is too large and the text is overloaded with jargon and terminology, we withdraw. If we are looking for details, we get lost in the shrubbery.

This issue is fascinating on an individual basis, but even more, problems are brought by the social scientific life. It is known that the more developed a branch of knowledge, the greater the stock of specialist terminology, words and concepts that become incomprehensible to most users. As early as 1934, the conceptual apparatus was described by Kazimierz Ajdukiewicz ${ }^{3}$ as a kind of basic tool determining our image of the world. However, the same apparatus that can be a great discovery is wordless jargon for most users. As noted in the introduction, biologists dealing with the language of "cavemen", i.e. inter-and multidisciplinary groups studying the life of caves: "[...] in the era of interdisciplinarity, the use of jargon may hinder effective communication between scientists who do not have a common scientific background". Italian researchers refer to earlier Swedish studies on the "readability" of scientific texts ${ }^{4}$. The cult of jargon has been criticized many times, but most notably in a 1989 article by Scott L. Montgomery ${ }^{5}$.

Martínez and Mammola investigated the relationship between jargon use and citation. This thing is essential for scientists and scientific life, especially since 2005, when Jorge E. Hirsch published his famous article on measuring the impact of publications. The Hirsch index $(\mathrm{h} \text {-index })^{6}$. Italian researchers, an evolutionary biologist and ecologist, used 21,486 articles of "cavemen" (or less literally simplification: "caveologists"). This discipline was particularly well suited to research - linguistic differences often occur between researchers, and not only among those who represent different scientific disciplines. Martínez and Mammola concluded, "a significant negative relationship between the proportion of jargon words in the title and abstract and the number of citations received by the article." So, suppose you take into account that database search algorithms and real readers treat abstracts and key-

3 Ajdukiewicz K., Obraz świata i aparatura pojęciowa [Das Weltbild und die Begriffsapparatur], „Erkenntnis”, IV, 1934, p. 259-287.

4 Plavén-Sigray P., Granville J.M., Schiffler B.Ch., Thompson W.H., The Readability of Scientific Texts is Decreasing Over Time, ed. King St., eLife 6 (5.09.2017): e27725. DOI: 10.7554/eLife.27725.

5 Montgomery S.L., The cult ofJargon: Reflections on language in science, "Science as Culture”, no. 1, 6 (1.01.1989): p. 42-77. DOI: 10.1080/09505438909526248.

6 Hirsch J.E., An Index to Quantify an Individual's Scientific Research Output, "Proceedings of the National Academy of Sciences”, no. 102, 46 (15.11.2005): p. 16569-72. DOI: 10.1073/pnas.0507655102. 
words as "attractors". In that case, it becomes understandable that scientists are called to delegate jargon to only those fragments of articles where its use is inevitable and to get rid of the excess of specialist terminology with abstract and keywords.

The authors of the cited work admit that the jargon, although difficult at first, to concentrate years of knowledge in a precise mental picture, is the essence of past scientific research, an abbreviation of the scientific achievements of its predecessors. Here they use the Russian "matryoshka" metaphor: each subsequent term enriches the initial message with new information, organizing and systematizing the concepts in the scientific corpus. In conclusion, Italian researchers state that while the jargon can significantly help convey ideas, thanks to condensation, it more often contributes to the division into artificially defined "experts" and "amateurs," thus strengthening the isolation of scientists in their world-famous critics academic - ivory towers.

\section{Perfect resolution}

From the above considerations, it can be concluded that jargon should in principle be avoided, but this would be a wrong conclusion: in an abstract, which is not a mere summary, it is necessary to achieve the appropriate perceptual resolution of the virtual reader. So part of the Wikipedia [polish] definition sounds incorrect:

Abstract - a summary of a scientific publication or book, in which, in a condensed form with as many keywords as possible, basic information about the thesis of the article, the methodology of the conducted research, the most important results and conclusions is contained ${ }^{7}$.

[underline - J.P.]

In this context, an abstract is not simply a summary, nor is it a maximum condensation with as many words as possible. Moreover, according to Martínez and Mammola, there is another conclusion: in abstracts, appropriate perceptual resolution of specialist terminology should be achieved if we write an article that is then indexed in databases. However, if we apply for grants, it is better to be as expert as possible: the grant applications full of jargon were always the most successful. After all, publicly available abstracts are read only by those willing to read them themselves, while a narrow group of specialists evaluates grant abstracts - they evaluate them, placing them in a broader perspective of strictly specialist knowledge.

The ideal resolution in scientific articles must not be the exact resolution that would be required from the point of view of science communicators. After all, saturation with specialist terminology is gradual.

pl.wikipedia.org/wiki/Abstrakt. 


\section{A QUICK COURSE ON WRITING ABSTRACTS ${ }^{8}$}

The abstract expected by scientific journals and publishers today should be more than just a few sentences about the publication or a traditional "summary." More extended abstracts (but not too long!) An ordered structure require databases, for which good text indexing is essential. Moreover, good indexing of a scientific text means the same as search engine positioning for the $\mathrm{SEO}^{9}$ industry - it is not objectification or commercialization of science. It is inevitable progress. It is worth realizing that we are not writing the article's abstract only for the "living" reader, let alone for an expert in our field (unless we are applying for a grant).

The APA style (American Psychological Association), often used as a model for researchers, also includes guidelines for constructing an abstract ${ }^{10}$. First, it should be treated as a summary of the article covering the research problem, our hypotheses, methods and research results, not as an abstract. What do specialists advise?

The recommended length of the abstract is approx. Two hundred fifty words (here, different versions may differ slightly from each other). Usually, you do not specify a minimum number of characters, but it is worth having an abstract of at least 200 words (although APA style refers to at least 150 words) - this allows you to include more keywords and key phrases searched by databases. Abstracts ranging from 200 to 300 words are recommended to journal editors, for example, the Scopus database. For abstracts in Polish, the size of the number of characters with spaces is often given - an English abstract of approx. Two hundred fifty words, which corresponds to a Polish abstract of approx. 1600-1800 characters.

The editors or publisher can explicitly specify the formatting of the text, and if it is not, it is advisable to stick to the standards: margins set to 1 inch $(2.54 \mathrm{~cm})$, bold headline, use of a readable font (e.g. Times New Roman 12), not to exceed the limit of 200-250 words. Separate keywords should be attached to the abstract - usually from three to five. They are used by databases for indexing and allow others to find our publication easily, so it is worth choosing the words that best relate to the research we write about.

An abstract is a separate text attached to a publication that informs the reader about the article's content or the book itself. Therefore, it is best to check it and think it over after finishing the publication when we already know all the conclusions. It is worth taking care of organizing the content of the abstract. For this purpose, you can use example questions and answer them with one or two sentences without overusing the jargon:

- What is the main topic of work? - outline the research goal, questions, theses or hypotheses;

- What studies have been conducted? - explain research methods;

- What has been found through the research? - summarize the most important findings/effects;

- What conclusions can be drawn from the research? - provide an interpretation.

8 The last - practical - part of the essay was published in a condensed form as materials prepared for the University of Lodz Library.

9 Search Engine Optimization. You should know that there is also ASEO, or Academic Search Engine Optimization - openjournalsystems.com/academic-search-engine-optimization. 


\section{Research goals}

Start by clearly identifying the research problem. What practical or theoretical problem does your research solve? What questions are you answering? Define the purpose of your research. Use words to describe the activities you performed while conducting the research, e.g. "analyze," "check," "research." You can use the present or the past tense, but rather not the future tense - we refer to research that has already been carried out. So instead of writing: "This study is to check the relationship between ..." - write: "This study checks the relationship between .... You can add a short piece of information about the research context, be it social or scientific, but without going into details.

\section{Methodology}

Indicate the research methods used in the research. Ideally, this part should be in a sentence or two. The past tense can be used because the activities have already been performed, e.g. "A survey was conducted among employees and students .... Do not evaluate the methodology — the abstract is only to familiarize the reader with it.

\section{Findings}

Summarize the main research results. You can use the present or the past tense, e.g. "Analysis has shown that...," "Tests prove.... You do not have to include all the research results, which are sometimes complex, in your abstract. All you have to do is highlight the most critical findings that familiarize the reader with the research.

\section{Conclusions, summary}

Finally, present the main conclusions that can be drawn from your research. Did you manage to answer the question / achieve the research goal, and how? If there are significant limitations to your research or your research needs to be continued, mention it.

Avoid citing sources in the abstract! The abstract should be fully understood without referring to other sources. References in abstracts may only be found in exceptional situations, e.g. when an article is a response to another article or directly refers to other research and would be incomprehensible without context.

It is worth remembering that the most important currency is a $\mathrm{n}$ abstract in English, and you should pay attention to grammatical correctness, e.g. using the appropriate past tense. If you are not sure about the correctness of the written text, it is always a good idea to consult a professional or read other abstracts in your discipline. An abstract in English is very important, even if you write in Polish or in another language - currently, the development of technology allows for immediate machine translation from even the most exotic language for the user, but it is the abstract that must encourage the potential reader to make an effort to learn whole.

\section{So how do you write a good abstract?}

1. Do not write a summary; write an abstract!

2. When writing an abstract of an article indexed in open access databases, consider saturation with terminology and limit it to the necessary minimum. 
3. When writing an article, do not avoid specialized language, but limit it to essential places. In the abstract, try to avoid jargon.

4. When applying for grants, write a project and abstracts in a specialized language: you write them for specialists highly valued by the community, not for laypeople.

5. If you speak to people, speak their language - preferably the simplest, most-used words.

JAROSŁAW PŁUCIENNIK

(iD) https://orcid.org/0000-0001-6984-7734

$\mathrm{PhD}$, Professor Ordinarius of the Humanities, interested in cultural studies, literature, cognitive science. He is affiliated at University of Lodz, Institute of Contemporary Culture, Chair of Theory of Literature, ul. Pomorska 171/173,90-236 Lodz, Poland, editor-in-chief of "The Problems of Literary Genres", former pro-vice-Rector of the University of Lodz.

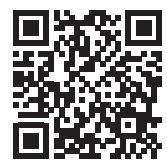

Contact: jaroslaw.pluciennik@uni.lodz.pl

Anna Zatora

https://orcid.org/0000-0003-4597-5568

PhD in humanities, a literary researcher, editor of "The Problems of Literary Genres". She works at the Department of Scientific Information and Bibliometric Analysis of the University of Lodz Library - 32/38 Jana Matejki St., 90-237 Lodz.

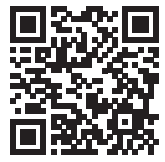

Contact: anna.zatora@lib.uni.lodz.pl 
The above text is not a scientific article.

But what could the abstract of such an article look like?

\begin{tabular}{|c|c|}
\hline Abstract & Headline \\
\hline $\begin{array}{l}\text { In the article, we examine the need to adapt the abstract of an article or } \\
\text { other scientific text to the recipient and scientific indexing content by } \\
\text { scientific search engines and databases. We argue that the summary is } \\
\text { not the same as the abstract and must have a specific shape and that the } \\
\text { degree of use of specialist terminology is of great importance for the } \\
\text { visibility of the text on the web. }\end{array}$ & $\begin{array}{c}\text { Defining the research } \\
\text { objective and thesis }\end{array}$ \\
\hline $\begin{array}{l}\text { Due to the development of scientific communication and publishing in } \\
\text { the open-access model, authors should master the basics of abstractology. } \\
\text { Research funding agencies, scientific institutions, research centres and } \\
\text { the public expect it from them. The dissemination and popularization } \\
\text { of science are associated with the visibility of research results and the art } \\
\text { of writing abstracts. }\end{array}$ & Research context \\
\hline $\begin{array}{l}\text { The research was based on the authors' experience, observation of the } \\
\text { scientific community and available texts on scientific jargon/terminology, } \\
\text { abstract writing methods and ASEO techniques. }\end{array}$ & Methodology \\
\hline $\begin{array}{l}\text { The analysis showed that the abstract of a scientific text is better indexed } \\
\text { by scientific databases and search engines when it contains keywords and } \\
\text { phrases and that the abstract written in a language understandable to } \\
\text { the recipient is read more willingly and helps to disseminate the theses } \\
\text { contained in the article. }\end{array}$ & Results \\
\hline $\begin{array}{l}\text { It follows that the abstract should be written in accordance with the } \\
\text { possibilities and limitations of tools indexing scientific texts and tailored } \\
\text { to the recipient depending on his competencies: we will write an abstract } \\
\text { differently for experts evaluating scientific grants and different when it is } \\
\text { to popularize science outside the academic environment. Terminology } \\
\text { should be used sparingly. The abstract is worth repeating the keywords } \\
\text { for the article itself, but without overusing the jargon. }\end{array}$ & Conclusions \\
\hline Keywords: abstract, abstractology, scientific style, ASEO & Keywords \\
\hline
\end{tabular}

